\title{
Conciliación, mediación y emociones: Una mirada para la solución de los conflictos de familia ${ }^{1}$
}

\section{Conciliation, mediation and emotions: A look for the solution of family conflicts}

Recibido: 04 de mayo de 2016 - Revisado: 2 de octubre de 2016 - Aceptado: 24 de abril de 2017

\section{Adriana Patricia Arboleda López ${ }^{2}$}

\section{Resumen}

La conciliación y la mediación, en calidad de mecanismos alternativos de solución de controversias, incorporan la idea de la interdisciplinariedad como la nueva tendencia nacional e internacional en la búsqueda de soluciones no violentas y que sean constructoras de paz, para la solución de conflictos socio-jurídicos, en particular para los asuntos que competen al Derecho de familia pues en estos casos, especialmente, se involucran los sentimientos y las emociones de las partes implicadas, los cuales tienen profundas raíces psicológicas. Por ello, la actual necesidad de que los abogados sean éticos, mediadores, conciliadores, y capaces de integrar saberes de diferentes disciplinas, para brindar una solución integral a los conflictos, especialmente a los de familia, dada la importante relevancia vigente de esta como célula fundamental de la sociedad.

\section{Palabras clave}

Mediación, conciliación, conflictos, familia, interdisciplinariedad, ética, emociones.

\begin{abstract}
Conciliation and mediation, as alternative dispute resolution mechanisms, incorporate the idea of interdisciplinarity as the new national and international trend in the search for non-violent solutions that are peace builders, for the solution of socio-legal conflicts. In particular for matters of family law because in these cases, especially, the feelings and emotions of the parties involved are implicated, which have deep psychological roots. Therefore, the current need for lawyers to be ethical, mediators, conciliators, and capable of integrating knowledge from different disciplines, to provide an integral solution to conflicts, especially those of family, given the important current relevance of this as a fundamental cell of society.
\end{abstract}

Keywords

Mediation, conciliation, conflicts, family, interdisciplinarity, ethics, emotions.

\footnotetext{
${ }^{1}$ Este artículo original es producto de la investigación "Mecanismos Alternativos de Solución de Conflictos: en particular la conciliación y la mediación interdisciplinar, para promover la cultura de acuerdos" desarrollado y financiado en la Universidad Autónoma Latinoamericana Unaula.

2 Postdoctoranda en Derecho en la Universidad Nacional. Posdoctora en Educación con enfoque en Complejidad e Investigación Transdisciplinar de la Universidad Simón Bolívar de Barranquilla. Doctora en Derecho Procesal Contemporáneo. Magíster en Derecho Procesal de la Universidad de Medellín, Especialista en Derecho Administrativo de la Universidad de Medellín, Abogada conciliadora de la Universidad de Medellín. Docente investigadora asociada de la Universidad Autónoma Latinoamericana Unaula. Miembro de la Red de Derecho Procesal, y de la Red de Consultorios Jurídicos y sus Centros de Conciliación de Antioquia.

Correo electrónico: adriana.arboledalo@unaula.edu.co

Para citar este artículo use: Arboleda, A. (2017). Conciliación, mediación y emociones: Una mirada para la solución de los conflictos de familia. Civilizar Ciencias Sociales y Humanas, 17(33), 81-96. doi: $10.22518 / 16578953.900$
} 


\section{Introducción}

\author{
No se puede desatar un nudo sin saber cómo \\ está hecho.
}

Aristóteles.

La mediación es uno de los Mecanismos Alternativos de Solución de Conflictos, (de ahora en adelante, MASC), por el cual, mediante un procedimiento, las partes enfrentadas son asistidas por una o más personas imparciales (mediadoras), quienes cuentan con métodos para el manejo de las emociones que se liberan en los conflictos, así como con técnicas para aislar e independizar los asuntos en los que se difiere, con el fin de alcanzar opciones de acuerdos que satisfagan los intereses de cada una de las partes involucradas en la pugna.

En referencia a las emociones, estas son generadoras de conductas humanas. Abordar e interpretar el comportamiento de las personas y la interacción con los demás al solucionar sus conflictos, constituye una situación compleja que involucra diferentes disciplinas, unidas intrínsecamente por relaciones de codependencia (Filosofía, Sociología, Psicología, Derecho, Comunicación, entre otras). En cuanto al Derecho tradicional, este se limita al estudio de las conductas humanas que tienen incidencia en la transgresión normativa; debido a su formación exegética, positivista, reducida al acatamiento de la ley, deja de lado el estudio y el conocimiento de las emociones presentes en todos los conflictos socio-jurídicos y en particular en el conflicto familiar ${ }^{1}$.

Tanto el mediador como el conciliador desempeñan un papel fundamental en la solución consensuada entre las partes en conflicto; deben ser neutrales e imparciales, con alto sentido de vida, espíritu altruista y que reconozcan la importancia del "otro" como ser humano. El término es usado indistintamente en algunas instancias nacionales e internacionales. A juicio de la investigadora, existen algunas diferencias: el conciliador propone fórmulas de arreglo, mientras que el mediador promueve la concertación desde el mismo sujeto de acuerdo con su libre albedrio, basado en el principio de la autonomía de la voluntad y en la libertad que cada ser humano tiene para concertar o no sus diferencias. Tanto en la mediación como en la conciliación, no existe un fallo impuesto, sino un acuerdo alcanzado en un ambiente de diálogo y de entendimiento del otro, según sus necesidades, derechos y posibilidades. Con estos mecanismos se debe lograr una salida no solo a lo contractual o legal, como se daría en la sentencia que dicta el juez, sino también una solución integral que evidencie el conflicto como oportunidad para restablecer los canales de comunicación rotos; por ejemplo, en el conflicto de familia, promoviendo el relacionamiento con el otro para una mejor convivencia.

La conciliación y la mediación, como mecanismos alternos, evitan que las partes acudan a un órgano jurisdiccional, que conlleve a un pleito o hacia el litigio, que es costoso, dispendioso y que genera desgastes económicos, anímicos y emocionales a las partes, además del conflicto que ya está presente. Como lo expresa el profesor Taruffo (1999), la jurisdicción ordinaria o vía judicial se encuentra en crisis por la falta de eficacia de la tutela jurisdiccional que deriva esencialmente "de los retrasos cada vez más largos de la justicia, frente a la creciente necesidad de soluciones rápidas y eficaces de las controversias" (p. 14).

Para desarrollar el concepto de la convivencia con los demás, Suárez (2007) nos dice que es diferente hablar de la convivencia en general que hablar de la convivencia directa con el otro; anota que la diferencia en esta relación se encuentra en la vida y en la situación de las personas, donde cada una de ellas se posee a sí misma, tomando en cuenta su realidad, la de la sociedad y la del mundo en el que vive, pues hay diversas formas de encontrarse y de "abrirse" al otro. Además Zubiri (1986), hablando de la responsabilidad que cada uno tiene con los individuos de la sociedad, señala: 
La razón última de la diferencia es que, formalmente hablando, la sociedad no tiene vida. No hay vida social, la vida la tiene cada una de las personas que están inmersas en ella. Lo único que hay son las vidas de cada cual socialmente tomadas (p. 302).

Por tanto, la convivencia pacífica en cualquier entorno puede verse afectada por los conflictos "inherentes a la coexistencia social" (Márquez, 2013, p. 27), los cuales surgen de la divergencia, la contraposición de necesidades, la búsqueda de intereses particulares, la disputa de recursos de cualquier naturaleza, especialmente cuando estos son escasos y están personificados. Los conflictos siempre estarán presentes en la naturaleza humana por lo que es inevitable que se presenten en la familia; la forma en que se abordan estos desacuerdos es lo que marca la diferencia, aceptándolos como oportunidad para mejorar las relaciones familiares.

En la nueva concepción de la formación de los abogados, se propone el conocimiento, divulgación y, poco a poco, el posicionamiento de los diferentes Mecanismos Alternativos de Solución de Conflictos (MASC), sin necesidad de pleitos o litigios. Esta evolución académica requiere que los abogados conciliadores y mediadores, se fortalezcan en el estudio de la ética, de las humanidades y de las emociones, su influencia en el autocontrol y la racionalidad, para lograr la solución de conflictos de forma pacífica a través de acuerdos.

Para alcanzar ese fin, muchos de los estudiosos de la materia han propuesto lineamientos enfocados en la "educación emocional", cuya base es comprender el actuar propio y el de los otros, además del fortalecimiento del diálogo y la asertividad en las relaciones interpersonales.

Con base en todo lo anterior, este artículo expone en primer lugar el papel de la mediación y la conciliación en el Derecho contemporáneo, seguido por la conceptualización de las emociones y su influencia en el Derecho, principalmente en los conflictos de familia, así: i. Importancia de la mediación y la conciliación en el Derecho; ii. Algunas de las diferencias entre mediación y conciliación; iii. Bases filosóficas y teóricas de las emociones, desde pensadores como Aristóteles hasta algunos más contemporáneos; iv. Las emociones en los conflictos de familia.

\section{La mediación y la conciliación en el Derecho}

La mediación y la conciliación son algunos de los MASC que permiten la concertación y los acuerdos basados en el principio de la autonomía de la voluntad. Su campo de desarrollo es muy amplio y en Colombia prometen ser herramientas socio-jurídicas de mucho futuro, incluso para temas como el posconflicto.

En Colombia la mediación no está regulada; actualmente no existe una ley concreta que la soporte, a diferencia de otros países como Alemania y España, en los que ya se goza de regulación, difusión y conocimiento, a través de la Ley 5 de 2012 -para toda la Comunidad Europea-, de mediación en asuntos de familia, civiles y mercantiles.

Teniendo en cuenta los diferentes conflictos que se pueden abordar extrajudicialmente por medio de la aplicación de los MASC, es evidente que pueden emplearse en diferentes ámbitos, como es el caso de las organizaciones; también para la solución de las controversias de convivencia; para la disolución de altercados en el escenario escolar a partir del conocimiento, aplicación y promoción de la mediación escolar; y, muy importante, en la resolución de problemas familiares. Sin embargo, hay que señalar la poca difusión de los mismos en las facultades de Derecho del país, encontrando incluso que en algunas Universidades se estiman estos temas como asignaturas electivas o de segunda importancia, otorgándole preferencia a la formación tradicional y/o con una inclinación a la formación litigiosa, memorizando códigos y leyes. 
La investigadora considera que en Latinoamérica, los MASC fueron concebidos como estrategia de fortalecimiento del marco institucional de los Estados y se les ha dado el rango de figura constitucional, pues en muchos países encuentran su soporte en la norma fundamental. En el caso de Colombia, aparecen establecidos en el Artículo 116 de la Carta Magna, en el que se sitúa a la mediación, la conciliación y el arbitraje, como formas transitorias para administrar justicia y para solucionar las controversias jurídicas, complementarias al aparato judicial; incluso determina puntualmente que los conciliadores $\mathrm{y}$ árbitros administran justicia transitoriamente, cuando acompañan a los particulares que buscan ante todo la convivencia pacífica, la paz y la reconstrucción social. Sin embargo, la aplicación de los MASC presenta algunos inconvenientes, entre ellos se pueden enunciar: su desconocimiento por parte de la sociedad en general, la escasa destinación presupuestal por parte del Estado colombiano, la falta de cultura de diálogo, el poco respeto por el otro, la ausencia de técnicas para identificar y comprender las emociones de las personas en conflicto.

Se plantea la idea de formar abogados dialógicos aptos para resolver, teniendo en cuenta la ética así como las emociones de los implicados, problemas socio-jurídicos complejos con enfoques inter, multi y transdisciplinar, y que contribuyan a la transformación de las prácticas legislativas en los consultorios jurídicos y en los centros de conciliación de las Universidades, de manera que en estas esferas, se dé prioridad a la ética, se resalte la importancia del ser humano, y que sus acciones se orienten en pro del bien común, bajo sólidos principios humanistas de justicia y de respeto por la dignidad humana, promoviendo los MASC como cultura de acuerdos.

Si bien perder o ganar no representan el único resultado de solución de conflictos, el Derecho conlleva a la imposición de un fallo donde siempre existe un ganador y un perdedor. Mientras que el acuerdo permite la solución consensuada, en el que las mismas partes libremente se obligan a lo que deben cumplir, el Derecho, entendido como ese conjunto de normas que regulan las relaciones de las personas en un marco de legalidad, se enfoca en una importante medida; en la atención a la conducta que despliegan los seres humanos y que afecta a los otros.

El principio de la autonomía de la voluntad, que se cimienta en el asentimiento de que las partes establezcan por sí mismos las reglas por las cuales van a ir encaminando o direccionando sus uniones, tanto civiles como familiares y comerciales, fundamenta la posibilidad de que las partes puedan, de igual manera que forman sus relaciones, solucionar los conflictos que se suscitan en razón a esos nexos que libremente crearon.

Pero no siempre es así, pues este principio, que fue creado mediante la concepción del Estado liberal en función de la libertad del individuo, evoluciona a medida que se implementan diversas formas de Estado en el mundo. Cuando el Derecho se transforma, también lo hace este principio. Surge así, a partir del Estado Social de Derecho, una concepción moderna en la que se le da al individuo un poder dispositivo, pero sometido al ordenamiento jurídico, como claramente lo ha dejado establecido la jurisprudencia de la Corte Constitucional en Sentencia T-668 de 2003:

Lejos de entrañar un poder absoluto e ilimitado de regulación de los intereses de los particulares, como era lo propio del liberalismo individualista, se encuentra sometido a la realización de la función social de la propiedad privada y de las libertades básicas de la economía de mercado.

Hoy en día este principio se encuentra definido, en gran parte, por el ordenamiento jurídico, empezando por la Constitución Política de Colombia a través de diversos derechos allí 
consagrados, tales como: el reconocimiento de la personalidad jurídica (Artículo 14); el libre desarrollo de la personalidad (Artículo 16); el derecho a la propiedad privada (Artículo 58), y la libertad de asociación (Artículo 38); así como en el Código Civil y en el Código de Comercio, que impulsan la libre conformación de relaciones jurídicas cubiertas por deberes legales y lineamientos básicos de conformación.

En Derecho, el desarrollo normativo, además de permitir la conformación de relaciones jurídicas, también establece la manera como las personas pueden dar por terminados algunos asuntos de los que pueden disponer, quiere decir esto, que son transigibles o conciliables; para ello, el Derecho creó los Mecanismos Alternativos de Solución de Conflictos, a los cuales pertenecen la mediación y la conciliación. En efecto, en Derecho, las partes pueden, de manera autocompositiva ${ }^{2}$ o heterocompositiva ${ }^{3}$, alcanzar acuerdos que den por finalizados los conflictos que se susciten entre ellos.

\section{Algunas de las diferencias entre mediación y conciliación}

En Derecho, la mediación es unmecanismo autocompositivo de solución de conflictos, lo que significa que la solución la encuentran y la proponen las mismas partes. Contrario a esto, en la conciliación es el conciliador quien propone fórmulas de arreglo, puesto que esta última es más intervencionista. Hay que resaltar que en Colombia, para determinados casos y materias, y a diferencia de Alemania y España, se tiene establecida la conciliación como un requisito de procedibilidad $^{4}$ y como presupuesto procesal de la acción ${ }^{5}$, para acceder a la administración de justicia.

Se ha de señalar que cuando en Colombia se exige la conciliación como requisito de procedibilidad por medio de la ley para acceder al aparato judicial, se presenta una confusión: se impone tal requisito para impulsar la conciliación, pero ello se impone a un derecho que de suyo, ya se tiene: acceder a la justicia ordinaria. Es decir que es innecesaria tal obligatoriedad para que un ciudadano pueda disfrutar de su derecho de acudir al aparato judicial, tal como sucede en países desarrollados como España, en donde la conciliación o la mediación no son prerrequisitos para poder demandar, sino que son una de las diferentes vías con las que se cuenta para solucionar las controversias socio-jurídicas. Adicionalmente, si se tiene en cuenta que la conciliación se basa en la autonomía de la voluntad, esta desaparece ante la citada obligación que el Estado impone, por cuanto el propietario del litigio no puede decidir libremente si quiere o no instaurar directamente el pleito o si desea arreglar sus desavenencias de forma rápida mediante el diálogo, escenarios totalmente diferentes. Cuando la conciliación se realiza ante los estrados judiciales, allí no se promueve el respeto por el otro, sino que se da cumplimiento a la exigencia legal. En algunos casos, ciertos abogados no explican a sus clientes las bondades de la concertación,-que se basa en la madurez del ser humano para resolver por sí mismo las desavenencias que se le presentan con otras personas-, ya sea por desconocimiento o porque tal vez estarían dejando de percibir los mayores honorarios que están establecidos para el tema del litigio. Esta última situación daría lugar a otra amplia discusión (que no se dará en el presente artículo), por cuanto culturalmente se cree que "es mejor un mal arreglo que un buen pleito", cuando podría ser lo contrario.

De otro lado, la Carta Fundamental en su Artículo 116, se refiere al conciliador como un particular imparcial investido transitoriamente de la función de administrar justicia, que presenta fórmulas de arreglo, donde las partes pueden o no aceptarlas o proponer por si mismas sus acuerdos; esta acción constituye, indudablemente, la aplicación directa del principio de la autonomía de la voluntad por parte de las partes implicadas en un conflicto.

Aunque en muchas ocasiones conciliación y mediación son términos que se emplean indistintamente, se debe de recalcar que 
el mediador no propone fórmulas de arreglo sino que facilita el acercamiento entre las partes, para que ellas mismas las encuentren. En cuanto a las leyes colombianas que reglamentan la forma como debe desarrollarse la conciliación ${ }^{6}$, están la Ley 23 de 1991, la Ley 446 de 1998 y la Ley 640 de 2001; en ellas se establecen las áreas del Derecho (familia, civil, comercial, laboral, administrativo y penal) en las que se puede emplear la conciliación. Es oportuno aclarar que existen dos tipos de conciliación en Colombia, la judicial y la extrajudicial. La primera se realiza dentro de un proceso judicial y quien actúa como conciliador es un Juez de la República; la segunda se realiza de manera privada y con anterioridad a un proceso judicial, mediante un procedimiento conciliatorio ${ }^{7}$.

Otra diferencia entre la conciliación y la mediación, es que la primera se rige por las normas previamente establecidas por los legisladores, mientras que la mediación se rige en mayor medida por las normas sociales, basándose en la noción que se tiene de justicia; además, en la conciliación es una obligación del conciliador presentar fórmulas de arreglo mientras que en la mediación se promueve el respeto por el otro, la libertad del sujeto, la importancia del ser humano, y el mediador solo puede dar una orientación sobre la manera en que se podría dar solución a los conflictos.

Por último, indicar que la mediación es un mecanismo informal que no está vigilado (excepto cuando es invocado como mecanismo de justicia restaurativa en el proceso penal), mientras que la conciliación, por ser un mecanismo legalmente establecido, debe cumplir con ciertos requisitos y formalidades para que el acuerdo sea válido, prestar mérito ejecutivo y hacer tránsito a cosa juzgada.

Ahora, se hace necesario realizar una reflexión sobre las emociones y cómo estas se encuentran inmersas en el proceso de mediación y/o conciliación.

\section{Las emociones: Fundamentación y teorías}

Para entender el papel que juegan las emociones y su importancia en la mediación y la conciliación, es preciso conocer su significado. Desde la antigüedad, algunos autores se han ocupado de este tema, como es el caso de Aristóteles, quien, en varias de sus obras como Ética a Nicómaco, la Ética a Eudemo y la Magna Moralia (título traducido en Español como "Gran Moral"); declaró las bases para conocer su origen y para su comprensión ${ }^{8}$.

Las emociones son mecanismos de reacción rápida en situaciones inesperadas y que se manifiestan de manera automática; además, son fenómenos inesperados que pueden derivarse en situaciones más simples De los Ríos (2014) afirma que "Cada persona experimenta una emoción de forma particular, dependiendo de sus experiencias anteriores, su aprendizaje $\mathrm{y}$ de la situación concreta. Algunas de las reacciones fisiológicas y comportamentales que desencadenan las emociones son innatas, mientras que otras pueden adquirirse" (p. 4). Aristóteles (2011c), en su obra La Retórica, nos dice que las emociones son las causantes de que los hombres cambien sus juicios:

Porque las emociones son, ciertamente, las causantes de que los hombres se hagan volubles y cambien en lo relativo a sus juicios, en cuanto que de ellas se siguen pesar y placer' ${ }^{9}$. Así son, por ejemplo, la ira, la compasión, el temor y otras más de naturaleza semejante y sus contrarias. Ahora bien, en cada una se deben distinguir tres aspectos ${ }^{10}$ : en relación a la ira -pongo por caso-, en qué estado se encuentran los iracundos, contra quienes suelen irritarse y por qué asuntos; pues si solo contamos con uno o dos de esos aspectos, pero no con todos, no es posible que se inspire la ira (1378 20 696).

Continuando con las reflexiones del Estagirita (como también se le conoce a Aristóteles), la ira es un apetito de venganza 
que se manifiesta por un desprecio contra sí mismo o contra los otros; el que la padece (el iracundo), se encoleriza contra un individuo en particular por algo que le ha hecho o que le iba a hacer a él mismo o a los suyos. Pasada la ira, el iracundo percibe cierto grado de placer ante la esperanza de vengarse y de aplicar un castigo (1378a30-1378b5 698).

En cuanto a la compasión, Aristóteles (2011c), la interpreta como un cierto pesar por la aparición de un mal destructivo y penoso en quien lo merece, que también lo podría padecer uno mismo u otra persona. Aquel que siente compasión está en la capacidad de creer que él mismo o alguno de sus allegados van a sufrir un mal. No sienten compasión los que están completamente perdidos, ni tampoco los que se creen muy felices, porque estos por lo general se encuentran 1lenos de soberbia (1385b15-22 731-733).

Por último, concibe el temor como una turbación que nace del presentimiento de que acontecerá, inminentemente, un hecho destructivo o penoso; son temibles por tanto, aquellos eventos que desplieguen un poder de destrucción o de provocar daños que lleven a estados de gran penalidad. El temor es causante de que se actúe rápidamente, y nadie debe hacerlo por desespero sobre las situaciones (1382 $20-1383^{\mathrm{a}} 10$ 716-719).

Aristóteles (2011a) considera el placer y el dolor como modos de ser en los individuos. En la Ética Eudemia, señala:

Las facultades ${ }^{11}$ y modos de ser están en relación con las emociones o pasiones, y éstas se distinguen por el dolor y el placer ${ }^{12}$. Los hombres son malos a causa de los placeres y de los dolores, por buscarlos y evitarlos o como se debe o los que no se debe (1221b351222a5 46).

En su Ética a Nicómaco (2010), relaciona directamente los placeres y dolores con la virtud ${ }^{13}$ moral: "Hay que considerar como una señal de los modos de ser el placer o dolor que acompaña a las acciones [...]. La virtud moral ${ }^{14}$, en efecto, se relaciona con los placeres y dolores, pues hacemos lo malo a causa del placer, y nos apartamos del bien a causa del dolor" (1104b5-20 56).

De los Ríos (2014) habla de seis categorías de emociones "básicas", y las clasifica y define como se observa en la Tabla 1:

Tabla 1. Categorías básicas de emociones

\begin{tabular}{|c|c|}
\hline CATEGORÍA & DESCRIPCIÓN \\
\hline Miedo & $\begin{array}{l}\text { Anticipación de una amenaza o } \\
\text { peligro (real o imaginario) que } \\
\text { produce ansiedad, incertidumbre, } \\
\text { inseguridad. }\end{array}$ \\
\hline Sorpresa & $\begin{array}{l}\text { Sobresalto, asombro, desconcierto. } \\
\text { Es muy transitoria y nos permite una } \\
\text { aproximación cognitiva para saber } \\
\text { qué está ocurriendo. }\end{array}$ \\
\hline Aversión & $\begin{array}{l}\text { Disgusto o asco hacia aquello que } \\
\text { tenemos delante. }\end{array}$ \\
\hline Ira & $\begin{array}{l}\text { Rabia, enojo que aparece cuando } \\
\text { las cosas no salen como queremos o } \\
\text { nos sentimos amenazados por algo o } \\
\text { alguien. }\end{array}$ \\
\hline Alegría & $\begin{array}{l}\text { Sensación de bienestar y de seguridad } \\
\text { que sentimos cuando conseguimos } \\
\text { algún deseo o vemos cumplida alguna } \\
\text { ilusión. }\end{array}$ \\
\hline Tristeza & $\begin{array}{l}\text { Pena, soledad, pesimismo ante la } \\
\text { pérdida de algo importante o cuando } \\
\text { nos han decepcionado. }\end{array}$ \\
\hline
\end{tabular}

Fuente: De los Ríos, 2014, p. 4.

Como se puede observar en la tabla anterior, existe una afinidad en la concepción que De los Ríos hace de las categorías de las emociones, con lo descrito anteriormente por Aristóteles; es el caso de miedo, la ira, la tristeza y la alegría; que sin duda alguna hacen parte de la étia y en especial de las teorías que se suscitan en la Retórica del Estagirita.

Sumado a la clasificación de las emociones, De los Ríos retoma el modelo de habilidades que orientaron Mayer y Salovey en 1999 y que son elementos de la teoría de la inteligencia 
emocional. Comprender las emociones y practicar dichas habilidades, aportarían considerablemente en la solución de problemas que se presentan en la vida diaria entre personas, y su aplicación se hace extensiva también al campo de la conciliación y la mediación, mucho más cuando se trata de resolver los conflictos de familia. El modelo de habilidades se consigna en la Tabla 2.

Tabla 2. Metodología propuesta por Mayer y Salovey para clasificar las emociones

\begin{tabular}{|c|c|}
\hline PASOS & $\begin{array}{l}\text { DESCRIPCIÓN } \\
\text { DE LA ACCIÓN }\end{array}$ \\
\hline Primer paso & $\begin{array}{l}\text { Se basa en la percepción, evaluación } \\
\text { y expresión de las emociones que se } \\
\text { refiere al conocimiento e identificación } \\
\text { de los sentimientos y la capacidad de } \\
\text { expresar adecuadamente cada una de las } \\
\text { emociones, en el momento oportuno y de } \\
\text { la forma correcta. }\end{array}$ \\
\hline Segundo paso & $\begin{array}{l}\text { Se estudia la asimilación o facilitación } \\
\text { emocional como la habilidad de tener } \\
\text { en cuenta las emociones para tomar } \\
\text { decisiones, que "puede facilitar el cambio } \\
\text { de perspectiva y la consideración de } \\
\text { nuevos puntos de vista". }\end{array}$ \\
\hline Tercer paso & $\begin{array}{l}\text { Se analiza la comprensión y análisis } \\
\text { de las emociones refiriéndose a la } \\
\text { capacidad de categorizar las emociones, } \\
\text { reconociendo las causas y consecuencias } \\
\text { de la emoción. }\end{array}$ \\
\hline Cuarto paso & $\begin{array}{l}\text { Se evalúa la regulación emocional como } \\
\text { la habilidad de moderar las emociones } \\
\text { negativas e intensificar las emociones } \\
\text { positivas, sin "reprimir" o exagerar la } \\
\text { información que comunica. }\end{array}$ \\
\hline
\end{tabular}

Fuente: De los Ríos, 2014, p. 6.

Eva Bach y Anna Forés (2010), acuden también a la inteligencia emocional y a partir de ella introducen cuatro categorías adicionales como son: la empatía, como la capacidad de percibir, sintonizar, conectar y comprender las emociones y sentimientos de otras personas; argumentan que esto es posible al interpretar las expresiones faciales o posición de sus cuerpos, las cuales traducirían las emociones que albergan los sujetos. La asertividad, basada en el respeto por uno mismo y por el otro, es la competencia de expresarnos y comunicarnos de un modo honesto, directo, respetuoso, para establecer relaciones más sanas y positivas. La resiliencia, entendida como la capacidad de salir victoriosos de una situación adversa o dañina. Por último, la serendipidad como la capacidad de convertir o percibir un hecho inesperado, un accidente o un hecho adverso, en una oportunidad de buena suerte.

Sumando lo anterior, existe otra clasificación de las emociones, que las separa en emociones primarias y secundarias; siendo las primeras, la cólera, la tristeza, la alegría y el miedo; y las secundarias, el amor, la sorpresa, la vergüenza y la aversión. Estas emociones influyen en la conducta de las personas al interactuar con otras, y revelan los sentimientos que les generan dichas relaciones (Berastegi, 2008). Se puede entender entonces que todas las conductas que desarrolla un sujeto, están mediadas por una emoción, ya sea primaria o secundaria. Según Monge (2014), estas emanan del cerebro y comprometen el acontecer de una actuación: "Los sentimientos son conscientes, objetos mentales como aquellos que desencadenaron la emoción (imágenes, sonidos, percepciones físicas...). Las emociones que no se perciben como sentimientos son inconscientes y, sin embargo, pueden tener efecto sobre nuestras conductas" (párr. 3).

Hablando de las acciones, es necesario aclarar que, de manera generalizada, hoy en día se declara que la intención es un elemento central en la comprensión de la noción de acción (González, 2009, p. 79); en la conducta, van vinculadas a las emociones de diversas maneras, tanto en la manifestación expresiva de las mismas, como en la intención; y vinculadas a los deseos, razones y sensaciones.

Aristóteles (2011a), relaciona la acción con los deseos y la elección:

Aquellas acciones que uno tiene en su poder hacer o no hacer, y aun aquellas que hace sin 
desearlas, las realiza voluntariamente y no por fuerza" (1225a10 57-58). Además, aquellas cosas que pueden ser o no ser, es posible deliberar sobre ellas y está en nuestro poder hacerlas o no (1226a20 62). Nadie elige sin estar preparado y sin haber deliberado si la cosa es mala o buena, y si, por otra parte, uno delibera sobre si la cosa es mala o buena, y si por otra parte, uno delibera sobre las cosas que, dependiendo de nosotros, pueden existir o no y que constituyen los medios para alcanzar el fin (1226b15 63). Es evidente que las acciones de las cuales el hombre es el principio y dueño, pueden suceder o no, y que de él depende que se produzcan o no, al menos aquellas de cuya existencia o no es soberano. Así de cuantas cosas está en su poder hacerlas o no, él mismo es la causa, y aquello de lo que es la causa depende de él; por tanto el hombre es la causa de las acciones voluntarias y conformes a su libre elección (1223a5-15 50).

Por tanto los deseos, en combinación con creencias instrumentales acerca de cómo satisfacerlos, son razones de la acción. Las emociones generan deseos previos; de allí el sujeto puede aumentar esos deseos o disminuir lo negativo causando deseos derivados; a estos se unen las creencias particulares que tenga cada persona, que junto con el deseo, generan la intención que deriva en la acción. Teniendo en cuenta que la persona decide aumentar o no esa emoción, no puede haber una predicción de la conducta que se va a desarrollar sino una interpretación de la misma cuando ya ha sido realizada (González, 2009, p. 79). En este orden de ideas, se destaca la importancia que tiene la educación emocional, ya que con ella se pueden prevenir acciones violentas o adversas a las normas, dado que es solo el ser humano quien puede, en últimas, decidir si aminora o aumenta la emoción negativa.

En suma, las emociones condicionan $\mathrm{u}$ orientan de manera directa las decisiones y el actuar de los seres humanos, de aquí la necesidad evidente de enfocar las diferentes ciencias del saber humano a su análisis. A continuación, se desarrolla el estudio en cuanto a la aplicación concreta de ellas en la mediación en familia.

\section{Las emociones en los conflictos de familia}

De acuerdo con lo expuesto hasta el momento, este estudio plantea que se hace necesario que en los MASC, pero específicamente en la mediación y la conciliación, se introduzca el análisis de las emociones teniendo en cuenta el contexto interdisciplinario de los mecanismos, y así, abordar los conflictos de una manera global para proponer soluciones eficaces a las diferentes problemáticas por las que se acude a esta figura.

La mayoría de las personas, al escuchar la palabra conflicto, la relacionan indudablemente con problemas, anomalías o con una situación que necesita ser resuelta de manera rápida para salir de ella. Pero, en el Derecho, el conflicto también puede ser entendido como una oportunidad de cambio, de mejoría, de desarrollo y de transformación de la vida y del relacionamiento de las familias y en general de toda la sociedad. El conflicto puede servir también para mejorar y fortalecer las relaciones interpersonales en los casos en los que se dialogue, se escuche y se armonicen las diferencias y las necesidades de cada uno de los involucrados en el conflicto.

Esta puede ser sin duda alguna, la primera manifestación de la relación entre Derecho y emociones: las emociones, como se ha venido exponiendo, además de ser antecedentes de la acción, también la condicionan, "por cuanto lo característico de las emociones no es tanto la vinculación con ciertas acciones concretas sino con ciertos objetivos" (González, 2009, p. 90). Recordemos que "entre las emociones y las acciones existe una conexión indirecta, mediada por las intenciones" (p. 93). Es así como se concluye que las emociones son la génesis y la explicación de la acción, y que la conducta puede ser comprendida desde un punto de vista no solo causal-mecanicista, sino también desde un punto de vista intencional o teleológico (De Carvalho, 2014, p. 10). 
Además de evidenciar que las emociones producen acciones, otro vínculo entre emociones y Derecho es el que sugieren Mayer y Salovey, cuando nos hablan de que se requiere de una inteligencia emocional que implica, para los individuos, tener la capacidad de controlar las emociones propias o de otras personas, distinguir las emociones y usar esa información para guiar su propio pensamiento, las propias acciones y las de los demás. Dado que las emociones conllevan en muchos casos a tener conductas delictivas de muchos órdenes, y que el analfabetismo emocional es el causante de la conflictividad, la violencia, el uso de drogas y demás males de la sociedad, se debería implementar que en el sistema educativo se enseñe a identificar las emociones y a controlarlas de una manera sana y consciente.

Teniendo en cuenta que el ser humano siempre está en relación con otros, es inevitable que los conflictos aparezcan como parte natural y cotidiana y, en mayor medida, en las relaciones familiares o de parentesco, dado que son el primer encuentro del ser humano con otros. Sin embargo, la forma en que las personas afrontan los problemas depende del grado de inteligencia emocional con el que cuenten. A pesar de que las emociones han sido casi totalmente descuidadas por los filósofos del derecho y, en general, por los juristas de tradición continental, no se puede decir lo mismo de los juristas anglosajones, quienes han introducido el movimiento law and emotion (Little, 2000, p. 13).

Varios escritores juristas y no juristas como Bernal (2013), Díaz (2013), González (2009), Orloff (2011), exponen en sus escritos no solo el papel fundamental que juegan las emociones en los conflictos, sino la importancia de incluirlas en los procesos judiciales como un componente de entendimiento del problema y la forma correcta de orientar la solución pacífica de los mismos. Este modelo sugiere entonces la pertinencia de articular el Derecho y las emociones, dado que estas determinan la conducta de los individuos, a lo que se suma la manera en que las personas abordan sus conflictos, dependiendo de la inteligencia emocional que dominen las partes involucradas en el problema. En consecuencia, es de suma importancia que mediador y conciliador reciban formación acerca de las emociones, pues ellos son los principales facilitadores y promotores de la comunicación asertiva y del diálogo, elementos fundamentales para la exitosa solución concertada de los conflictos de familia que se intentan resolver cuando los implicados acuden a la figura de los MASC.

En la familia, como pilar fundamental de la sociedad, es imprescindible que se les otorgue gran importancia a las emociones en el momento de establecer acuerdos que favorezcan la solución de los problemas que se desarrollan en torno a ella; contrariedades que no solo competen a cuestiones monetarias, contractuales o legales (como divorcios, demandas por alimentos, por la custodia de los hijos y por el cuidado personal de menores, entre otros), sino en mayor medida, a la ruptura o debilitamiento de las relaciones interpersonales, afectivas y sentimentales.

Por lo general, los conflictos de familia se inician porque una de las partes falla en la comunicación y esto genera, en la otra, remordimiento, infelicidad, temor, decepción o tristeza (emociones sobre las que ya se ha hablado en este escrito); el resultado: fraccionamiento de la relación, desacuerdos, y el surgimiento de posiciones contrarias que desembocan en conflicto o en su escalonamiento.

Cuando las partes enfrentadas han agotado los recursos para encontrar un punto medio o en común, y deciden recurrir a un tercero imparcial, llegan a la figura de los MASC para ser acompañados por un mediador o conciliador; este tercero debe lograr que los implicados se sientan tranquilos y confiados con su desempeño; así mismo, llevarlos a la comprensión, no solo del conflicto en términos normativos, sino de las percepciones y juicios que surgieron y 
que desembocaron en el conflicto que los ha llevado a acudir a ese método. Adicionalmente, es de gran utilidad para el mediador o conciliador, que identifique detalladamente las emociones que genera una parte con respecto a la otra.

Lo anterior no significa que el mediador o conciliador deba hacer un análisis psicológico de la persona ya que no es su campo del saber, pero sí ha de identificar los sentimientos o emociones (tales como frustración, dolor, rabia, tristeza, entre otras) que hicieron surgir el conflicto y llevarlo a estas consecuencias. Lo anterior con el objetivo de posibilitar la construcción de acuerdos, así como para establecer, de común acuerdo con ellos, que les asesore y acompañe un Psicólogo, con el fin de ayudarles a entender el porqué de sus reacciones en cada etapa de la negociación.

Con base en la experiencia de la investigadora, se puede indicar que la mayor parte de las mediaciones y conciliaciones que se tramitan en los Centros de Conciliación, son para resolver asuntos de familia; dada la cercanía que tienen las Universidades y sus consultorios jurídicos con los temas de proyección social ${ }^{15}$, el presente estudio destaca la necesidad de incorporar un Psicólogo en los procesos de mediación y conciliación, ya que muchas veces el conflicto surge o se intensifica por la empatía o no, más que por la disputa de derechos.

Lo que lleva inmediatamente a pensar que mediador y conciliador deben convertirse "[...] en un canal perfecto para limpiar la comunicación de las interpretaciones más subjetivas [...]" (Díaz, 2013, p. 202), o dicho de otra manera, servir como un puente de comunicación entre las partes, entendiendo las razones que les motivaron a tomar unas $u$ otras posiciones, y reconociendo las emociones que suelen manifestarse en el desarrollo de la mediación o de la audiencia.

Adicionalmente, el mediador o conciliador debe tener claro que la persona es la parte visible que contesta, que la sombra se manifiesta a través de las emociones para reaccionar, y que esa combinación es la que forma el yo de cada ser humano (Gelabert, 2010). Es decir, todo individuo tiene un conocimiento personal de lo que considera que él es y lo proyecta por medio de su forma de comunicarse, interactuar, caminar, hablar, y demás; la otra parte que desconoce de sí mismo, se proyecta en la medida en que manifiesta sus sentimientos.

Resumiendo, la tarea que deben desempeñar mediador y conciliador, consiste en comprender y luego expresar claramente, a cada una de las partes, la génesis del conflicto de familia; manifestar su posición de tercero imparcial como facilitador de los acuerdos; permtir que las partes manifiesten sus emociones, buscando la fuente de las mismas, con respecto a la situación específica; indicarles afablemente la percepción que tiene de las declaraciones aportadas al proceso, identificando detalladamente todas las emociones percibidas, de acuerdo con la manera de reaccionar de cada uno como respuesta al otro.

Retomando, mediador y conciliador han de tener muy presente que las emociones condicionan las relaciones, entonces, en las audiencias de conciliación en familia, esta comprensión no se ha de limitar solo a su propio entendimiento, sino en la extensión del mismo a todas las partes interrelacionadas en el conflicto. Adicionalmente, saber claramente por qué las partes del conflicto se comportan de cierta manera, y establecer entornos agradables que propicien la negociación (Gelabert, 2010). Tanto el mediador como el conciliador, no pueden tener complejo de superioridad o ser autoritarios, por el contrario, deben ganarse la confianza de las partes y avivar el ambiente de diálogo. Por otra parte, han de tener alta autoestima, ser altruistas, y un innato interés y respeto por el otro como ser humano.

Con base en todo lo anterior, debe adoptarse tanto para los MASC como para la prác- 
tica jurídica, la idea de que las emociones son fuente de intensión humana, que desencadenan el actuar de los sujetos, y que llevan a estar acorde o no al Derecho, teniendo en cuenta su idea personal de lo que es correcto o sus creencias firmes de lo acorde a la verdad y a la justicia. La habilidad de identificar las emociones y sentimientos en los demás, otorga al profesional una nueva pista de la manera correcta de abordar un conflicto para lograr así acuerdos que se lleven más en la práctica que en el papel, específicamente en el área de familia, donde son más radicales las posturas de cada parte.

Este estudio señala que se precisa que el tema de las emociones sea abordado en la formación de los Abogados, para que estos entiendan de una manera más próxima, las emociones y los sentimientos que se presentan durante los procesos de conciliación en un caso de familia. A pesar de que se trata de una formación humanista, se ha identificado que en los programas de Derecho el componente comportamental del ser humano no hace parte fundamental de los currículos, así como tampoco la relación con la Psicología u otras disciplinas sociales. Normalmente, sólo se encuentra esta relación en algunas asignaturas como la sociología jurídica, humanismo, cultura y valores y filosofía, materias que se encaminan directamente en la profundización de los conflictos basados en el "yo interno" de cada ser humano.

\section{Metodología}

Se utilizó el método hermenéutico a partir de un ejercicio de intertextualidad y con un enfoque de comprensión, donde se relacionaron los asuntos de las emociones desde un referente primario, como son algunas de las obras de Aristóteles, interpretadas en el contexto contemporáneo; además, se hizo una revisión de la mediación en Colombia para establecer una relación directa entre las emociones y la mediación, como elemento clave para la comprensión de los MASC en la actualidad.

\section{Conclusiones}

Con la implementación de la conciliación como actividad jurisdiccional, a partir de la puesta en marcha de la Constitución de 1991 en su Artículo 116, se dio un paso gigantesco en la generación de formas alternativas de acceso a la justicia (como lo manda el mismo ordenamiento superior); se le retiró al Estado la competencia exclusiva en la resolución de los conflictos y se permitió a los conciliadores administrar justicia de forma transitoria. Sin embargo, los Mecanismos Alternativos de Solución de Conflictos requieren de mayor conocimiento e investigación en el medio.

La conciliación y/o la mediación son Mecanismos Alternativos de Solución de Conflictos que humanizan el Derecho, promoviendo las soluciones integrales a los conflictos, reconociendo la importancia del otro como ser humano.

Es importante resaltar el papel determinante que juega el mediador $\mathrm{y} / \mathrm{o}$ conciliador para que las partes entiendan al otro y busquen la forma de consolidar acuerdos que permitan alcanzar la solución de sus conflictos; además, es relevante que conozcan que las emociones direccionan el comportamiento humano, por lo que los estudiosos de las áreas humanistas deben interconectarse para tener un mayor entendimiento, no solo de los conflictos, sino de la manera como el ser humano se proyecta al exterior.

Dada la trascendencia que la familia tiene en la estructura de la sociedad, los conflictos que se generen en su contexto se tornan especialmente importantes, por, lo que se sugiere que se implemente que durante los procesos de conciliación y mediación (y aún después de alcanzar acuerdos), intervengan profesionales de diferentes disciplinas para acompañar a las partes.

\section{Recomendaciones}

Que en la práctica de los consultorios jurídicos, la conciliación cumpla con la filosofía 
con la que fue creada, es decir, que para resolver un conflicto, las partes involucradas acudan al proceso conciliatorio de manera autónoma y voluntaria, y que este procedimiento no se constituya en una barrera o una condición para acceder a la justicia.

Que se fortalezca la cultura de la conciliación y que se genere conciencia en la ciudadanía de las ventajas que representan los MASC, entre ellas las económicas, para la solución de los conflictos. Esta labor ha de partir desde diferentes ámbitos: por parte del Estado, desde la Dirección de Métodos Alternativos de Solución de Conflictos del Ministerio de Justicia y del Derecho; en las Universidades, a través de sus servicios jurídicos y de los estudiantes de Derecho.

Promover desde la primera infancia y en el contexto escolar, la convivencia pacífica, la cultura del diálogo y la reconstrucción del tejido social, valiéndose de la figura de la mediación escolar.

Debido a la crisis del aparato judicial, que la figura de la conciliación, a través del diálogo de saberes interdisciplinarios, sea la vía para la solución integral de los conflictos socio-jurídicos.

\section{Notas}

1 Actualmente, la "estructura familiar" es comprendida no solo exclusivamente por la familia nuclear (compuesta por padre, madre e hijos); también se entiende por familia, una gama más amplia de estructuras familiares, por ejemplo hogares conformados por madres o padres solteros; menores de edad que conviven con sus abuelos o tíos; padres divorciados que conviven con sus hijos; familias ensambladas (en donde tanto la madre como el padre ya tienen hijos de otras relaciones); hermanos que conviven solos; madres cabeza de familia. Incluso en los nuevos tiempos, se habla de familia cuando son hogares formados por parejas homosexuales.
2 Hace referencia al hecho de que las personas, por sí mismas o con la ayuda de un tercero imparcial, puedan dar por terminado un conflicto; es decir que son las partes quienes en definitiva, llegan a un acuerdo sobre la solución más apropiada a su pugna.

3 Es una forma institucional de solucionar un conflicto: las partes acuden voluntariamente a un tercero, quien dirime el litigio conforme al Derecho e impone una decisión a las partes.

${ }^{4}$ La conciliación prejudicial es la que se realiza antes de acudir al proceso judicial como requisito de procedibilidad para iniciar la litis, es decir, como presupuesto procesal en algunas áreas del Derecho, entre otras en materia contenciosa administrativa, civil, comercial, y de familia. Esta situación tiene un espíritu altruista, pero, a juicio de la investigadora, si bien es ideal que las partes sean obligadas en alguna medida a buscar alternativas o a considerar la conciliación como un medio de resolver el conflicto antes de acudir al proceso judicial, cuando la ley estima la conciliación como requisito obligatorio para poder demandar, se considera que al ser impuesta, las partes no asisten libre y voluntariamente, principio característico fundamental de los libres acuerdos.

5 Los presupuestos procesales hacen parte de los requisitos mínimos de orden legal que se deben satisfacer para que ciertos actos, como la demanda, la denuncia o la querella, sean admitidos por el juez; con ello se le otorga la competencia para conocer el conflicto que se pone a su disposición e iniciar todo el trámite procesal tendente a tomar una decisión de fondo a través de una sentencia. Sin embargo, y a juicio de la investigadora, el uso de los MASC, y específicamente de la conciliación, deberían contar con su propia estructura desligada de la estructura del aparato judicial, garantizada directamente por el Estado.

${ }^{6}$ El término de conciliación es más usado en Colombia y Perú, países donde las 
normas que se refieren a este mecanismo, así lo consagran; no sucede lo mismo en otros países del mundo, como México, Brasil. España y Alemania.

7 Para más información se puede consultar la "Guía Institucional de Conciliación en civil" expedida por el Ministerio del interior $\mathrm{y}$ de Justicia en la siguiente dirección web: http://www.udea.edu.co/wps/wcm/connect/ udea/5fadc291-4ea0-4cfa-b054-3cc111122b24/ GuiaInstitucionalDeConciliacionCivil_ MinJusticia.pdf?MOD=AJPERES

8 En varias de las traducciones que se han hecho de la obra de Aristóteles, se emplea el término "pasiones" como sinónimo de "emociones".

9 En su obra Ética a Eudemo, Aristóteles (2011a) dice: "Entre estas mismas pasiones hay especies que reciben su nombre de las diferencias con respecto a un exceso de tiempo o de grado o con relación a uno de los factores de estas emociones. Digo, por ejemplo, de alguien que es ardoroso porque se enardece más pronto de lo debido; irritable y colérico, por alterarse más de los debido; amargo, porque retiene su enojo; pendenciero e injurioso, por los castigos que inflige a causa de su ira" (1221b10-17 45).

${ }^{10}$ En La Retórica (2011c) se dice que: "Esta triple distinción constituye el método que efectivamente sigue Aristóteles, de un modo regular, en su inmediato análisis de las pasiones [...]" (nota al pie 1378 696).

${ }^{11}$ Se encuentra en la Magna Moralia (2011b) que "Son pasiones la ira, el miedo, el odio, el ansia, la envidia, la piedad y las cosas semejantes, a las cuales suelen acompañar dolor y placer. Son facultades, en cambio, las realidades anímicas en virtud de las cuales se dice que somos capaces de sentir esas pasiones, como aquellas en virtud de las cuales somos capaces de sentir cólera, dolor, compasión y los sentimientos semejantes" (1186 7 147).
${ }^{12}$ El porqué de esto, lo dice en la Ética a Eudemo (2011a) de la siguiente manera: "Por eso, todos los hombres definen espontáneamente las virtudes como impasibilidad o serenidad respecto de los placeres y los dolores, y los vicios, por las relaciones contrarias" $\left(1222^{\mathrm{a}} 546\right)$.

${ }^{13}$ La virtud es la disposición que resulta de los mejores movimientos del alma, y es también la fuente de las mejores acciones y pasiones de esta (2011a, 1220a30-32 40-41). "Es por tanto, ese modo de ser que nos hace capaces de realizar los mejores actos y que nos dispone lo mejor posible a un mejor bien u obrar, que está acorde con la recta razón (1222a8 46-47). En la Ética a Nicómaco, Aristóteles (2010) define la virtud como "un hábito electivo que consiste en un término medio relativo a nosotros, regulado por la recta razón en la forma en la que lo regularía un hombre verdaderamente prudente. Es un medio entre dos vicios, uno por exceso y otro por defecto, y también por no alcanzar, en un caso, y sobrepasar en otro, lo necesario en las pasiones y acciones, mientras que la virtud encuentra y elige el término medio. Por eso, de acuerdo con su entidad y con la definición que establece su esencia, la virtud es un término medio, pero con respecto a lo mejor y al bien, es un extremo" (1106b-35-1107a-5 63).

${ }^{14}$ Se le denomina de esta manera por el hecho de ser fruto de la costumbre.

${ }^{15}$ Esta información pudo extraerse de la experiencia del Centro de Conciliación Juan Rafael Cárdenas Gutiérrez de la Corporación Universitaria Lasallista.

\section{Referencias}

Aristóteles. (2010). Ética a Nicómaco. Madrid: Editorial Gredos.

Aristóteles. (2011a). Ética Eudemia. Madrid: Editorial Gredos.

Aristóteles. (2011b). Magna Moralia. Madrid: Editorial Gredos. 
Aristóteles (2011c). Retórica. Madrid: Editorial Gredos.

Bach, E., \& Forés, A. (2010). La asertividad para gente extraordinaria. Barcelona: Plataforma editorial Barcelona.

Berastegi. J. (2008). Inteligencia emocional. Recuperado de http://www.blogseitb.com/in teligenciaemocional $/ 2008 / 12 / 01 / \% \mathrm{C} 2 \%$ BFcomo-se-clasifican-las-emociones/.

Bernal, T. (2013). La mediación una solución a los conflictos de pareja. Madrid: Colex.

Calhoun, R., \& Solomon, C. (1992) ¿Qué es una emoción?: lecturas clásicas de psicología filosófica. España: S.l. fondo de cultura económica de España.

Cárdenas, L. (2011). Aristóteles retórica, pasiones y persuasión. Colombia: San Pablo.

Constitución Política (1991). Congreso de la República de Colombia. Colombia.

Danto, A. (1981). Acciones básicas en cuadernos de críticas. México: Unam.

De Carvalho, V. (2014). Daniel González Lagier Emociones, responsabilidad y derecho. Madrid: Ediciones jurídicas y sociales S.A.

De los Ríos, A. (2014). Las emociones comprenderlas para vivir mejor (Asociación Española Contra el Cáncer). Recuperado de http:/www.apega.org/attachments/article/767/GUIAEMOCIONES_v2-1.pdf.

Decreto 410 de 1971. Por el cual se expide el Código de Comercio. Diario Oficial No. 33.339. Presidencia de la República, marzo de 1971.

Díaz, F. (2013). Conflicto mediación y conciliación desde una mirada restaurativa y psicojurídica. Medellín: Ibáñez.
Gelabert, M. (2010). Curriculum emocional. Aprender a ser. Recuperado de http:// es.slideshare.net/magdalena2vbk9k/educacin-emocional-y-resolutiva-frente-alos-conflictos

González, D. (2009). Emociones responsabilidad y derecho. Madrid: Marcial Pons.

Ley 57 de 1887. Con arreglo al artículo 52 de la Constitución de la República, declárase incorporado en el Código Civil el Título III (arts. 19-52) de la misma Constitución. Diario Oficial No. 7.019. Congreso de la República de Colombia, abril de 1887.

Ley 23 de 1991. Por medio de la cual se crean mecanismos para descongestionar los Despachos Judiciales, y se dictan otras disposiciones. Diario oficial No. 39.752. Congreso de la República de Colombia, marzo de 1991.

Ley 448 de 1998. Por medio de la cual se adoptan medidas en relación con el manejo de las obligaciones contingentes de las entidades estatales y se dictan otras disposiciones en materia de endeudamiento público. Diario oficial No. 43.345. Congreso de la República de Colombia, julio de 1998.

Ley 640 de 2001. Por la cual se modifican normas relativas a la conciliación y se dictan otras disposiciones. Diario oficial No. 44.303. Congreso de la República de Colombia, enero de 2001.

Little, L. (2000). Negotiating the Tangle of Law and Emotion. Recuperado de http://heinonline.org/HOL/LandingPage? handle=hein . journals $/$ clqv $86 \&$ div $=35 \& i d=\&$ page $=$

Mayer, C., \& Salovey, P. (1999). Emotional intelligence meets traditional standards for an intelligence. Intelligence, 27(4). 267-298. doi: 10.1016/S01602896(99)00016-1 
Márquez, C. (2013). La mediación proceso y derecho. España: Marcial Pons.

Monge, S. (2014). Diferencia entre emoción $y$ sentimiento. Recuperado de http:// neuromarca.com/blog/diferencia-entreemocion-y-sentimiento/.

Orloff, J. (2011). Libertad emocional. Cómo dejar de ser víctima de las emociones negativas. Miami: Ediciones Obelisco.

Reino de España. Ley 5 de 2012. De mediación en asuntos civiles y mercantiles. Boletín Oficial del Estado No. 162. Jefatura del Estado, julio de 2012.

República de Colombia. Ministerio del Interior y de Justicia. (2007). Guía Institucional de Conciliación en civil. Bogotá: Autor. Recuperado de http://www.udea.edu.co/ wps/wcm/connect/udea/5fadc291-4ea04cfa-b054-3cc111122b24/GuiaInstitu-
cionalDeConciliacionCivil_MinJusticia. pdf?MOD=AJPERES

Sentencia T-668 (2003, agosto 6). Acción de tutela. M.P. Marco Gerardo Monroy Cabra. Corte Constitucional.

Suárez, G. (2007). La persona: bioética y alteridad. Trabajo presentado en el VIII Seminario Internacional Bioética y Biojurídicade la "UniBoyacá", Boyacá, Colombia.

Taruffo, M. (1999). Racionalidad y crisis de la ley procesal. Italia: Doxa.

Valencia, C. (2014). Que son las emociones. Recuperado de http://www.las-emociones.com/que-son-las-emociones.html

Zubiri, X. (1986). Sobre el hombre. Madrid: Alianza Editorial. 